\title{
La élite mercantil judeoconversa andaluza y la articulación de la trata negrera hacia las Indias de Castilla, ca. 1518-1560*
}

\author{
Manuel F. Fernández Chaves \\ Universidad de Sevilla \\ mfernandez6@us.es \\ Rafael M. Pérez García \\ Universidad de Sevilla \\ rperez4@us.es
}

RESUMEN: El presente artículo estudia el proceso histórico por el que la élite mercantil judeoconversa de la Baja Andalucía jugó un papel decisivo en la articulación de la trata negrera hacia la América española en la época de Carlos V. Gracias a ello, resulta posible percibir el cambiante mundo de los negocios a Indias y las interrelaciones habidas entre los grandes grupos económicos involucrados en la misma durante la primera mitad del siglo XVI.

Palabras clave: Judeoconversos; Andalucía; Trata Negrera; América Española; Siglo XVI.

The Andalusian «Judeoconverso» Commercial Elite and the Construction of the Slave Trade to Spanish Indies, circa 1518-1560

ABSTRACT: In this paper, we study how the converso elite in Lower Andalusia had a crucial role in the development of the slave trade towards the Spanish America in the age of the Emperor Charles $V$. Considering this analysis, it is also possible to understand better the changing relationships of the

* Siglas: AGI (Archivo General de Indias). AGS (Archivo General de Simancas). AHPSe (Archivo Histórico Provincial de Sevilla). C (Contratación). CJH (Consejo y Juntas de Hacienda). IG (Indiferente General). J (Justicia). PNS (Protocolos Notariales de Sevilla). SD (Santo Domingo). Este trabajo se ha realizado en el marco del Proyecto de Investigación I+D «Nobles judeoconversos. El origen judío de las élites andaluzas (ss. XV-XVII)», financiado por el Ministerio de Economía y Competitividad de España (HAR2012-35752). 
most important economic groups involved in the atlantic businesses during the first half of the sixteenth century.

KEY WORDS: «Judeoconversos»; Andalusia; Slave Trade; Spanish America; XVIth Century.

\section{INTRODUCCIÓN}

El establecimiento del tribunal de la Inquisición en Sevilla y la persecución sufrida por los judeoconversos en el Reino de Sevilla en el tránsito del siglo XV al XVI afectaron gravemente la vida y la actividad económica de las grandes familias de origen converso. Muchos sufrieron procesos, cárceles, hogueras, y también exilios, especialmente en los cercanos estados señoriales de los Ponce de León, Guzmanes y Zúñigas, desde Sanlúcar de Barrameda hasta Gibraleón y Ayamonte ${ }^{1}$. Otros acabaron refugiándose en Portugal $^{2}$. La negociación y acuerdo de las composiciones de 1509 (en la que desempeñó un papel protagonista el financiero converso sevillano Pedro del Alcázar) y 1511 pusieron las bases para la normalización de la vida y la reactivación económica de algunas de aquellas familias ${ }^{3}$. Desconocemos hasta qué punto la presencia anterior de distintas comunidades de mercaderes italianos pudo haberse visto beneficiada por la sacudida sufrida por los conversos andaluces. El hecho es que a comienzos del siglo XVI se detecta una actividad dominante en todos los planos económicos (tanto comerciales como financieros) tanto de estos italianos (especialmente genoveses y florentinos) como de otros grupos, como el de los burgaleses ${ }^{4}$. Esta evolución del tejido social y de la estructura económica del Reino de Sevilla iba a acelerarse drásticamente por el hecho americano y el rápido desarrollo de las transacciones económicas entre el Mediterráneo y el Norte de Europa que tenían a Andalucía occidental como uno de sus centros de referencia. El presente trabajo muestra el papel de estas familias judeoconversas de raigambre andaluza en la construcción de los nuevos espacios atlánticos. Nos enfrentamos a un conjunto de familias estrechamente vinculadas entre sí por los lazos del matrimonio y de comunes intereses económicos y sociales: así sucede entre los Alcázar, Bazo, Prado, Caballero, Illescas, Sánchez Dalvo, Alemán, Gibraleón, Jerez, Núñez, o De la Barrera, entre otras ${ }^{5}$. Estas familias, junto a otras de judeoconversos andaluces

1 LADERO, 52/2 (Madrid, 1992). OLLERO, 40 (Madrid, 1988).

2 MONTES, 2006.

3 GIL, 2000-2003.

4 OTTE, 1996; PALENZUELA, 2003; PIKE, 1966.

5 Algunos datos básicos al respecto en: PIKE, 1978: 44-45 y 110. GIL, 2001, vol. 3: 342-343. Catálogo, 1930, vol. 1: 444. También, por supuesto, PEREZ, 2007. 
como los Córdoba-Torres, protagonizarán la construcción del sistema de la trata negrera hacia las Indias de Castilla durante el reinado del Emperador manteniendo alternativamente relaciones de competencia o colaboración con los poderosos lobbies genoveses y burgaleses, a quienes supieron relegar a un lugar secundario.

\section{Los COMienzos de LA TRATA NEGRERA EN El ATLÁNTICo}

La expansión portuguesa en el Atlántico durante la segunda mitad del siglo XV originó una nueva trata de esclavos africanos que, en principio, se dirigió fundamentalmente hacia la Península Ibérica, transformando la realidad de la esclavitud en las regiones costeras comprendidas entre Lisboa y Barcelona ${ }^{6}$. A partir de este momento, Andalucía occidental tuvo una numerosa población esclava negroafricana ${ }^{7}$. Lógicamente, ese tráfico estuvo dirigido por mercaderes portugueses, quienes controlaban las fuentes de abastecimiento en África. Por otra parte, el descubrimiento de América y la paulatina ocupación del Caribe por los castellanos produjo desde el segundo viaje de Colón los primeros traslados de esclavos negros hacia esta zona; a pesar de que en estos años la política de la Corona fue titubeante, desde 1509 quedó establecida la necesidad de disponer de una licencia real para poder llevar esclavos negros a las Indias ${ }^{8}$.

\section{LOS AÑOS DEL OLIGOPOLIO GENOVÉS-BURGALÉS (1518-1526) Y LOS PROBLE- MAS DE CONEXIÓN ENTRE LAS TRATAS NEGRERAS PORTUGUESA Y CASTELLANA}

A partir de la venida de Carlos I a Castilla se produjo una modificación sustancial del marco relativo a la introducción de esclavos en las Indias, poniéndose desde 1518 las bases del sistema por el que la Corona regularía hasta finales del siglo XVI la trata hacia ellas. Los grandes paquetes de licencias concedidos por el monarca en agosto y septiembre de 1518 marcan de forma clara el cambio de etapa: así, por cédula de 10 de agosto de 1518 se concedía a don Jorge de Portugal licencia para pasar 400 esclavos negros a las Indias; por otra de 18 de agosto de 1518 Lorenzo de Gorrevod (gobernador de Bresa, mayordomo del Rey y cortesano) obtenía licencia para enviar 4.000 esclavos negros en régimen de cuasi-monopolio (nadie más podría enviar esclavos mientras no se hubiesen llevado los de su licencia, salvo aquellos que disfru-

6 FONSECA, 2010. GONZÁLEZ ARÉVALO, 2006. CORTÉS ALONSO, 1964. ARMENTEROS, 2012.

7 FRANCO SILVA, 1979. PÉREZ GARCÍA, FERNÁNDEZ CHAVES, 2009: 597-622.

8 MIRA CABALLOS, 54/201 (Madrid, 1994): 273-297. 
tasen de una licencia con fecha anterior); y, por otra cédula de 27 de septiembre de 1518 se otorgó licencia al marqués de Astorga para pasar otros 400 esclavos negros a América (cien durante la vigencia de la licencia de Gorrevod, y los restantes tras su finalización) ${ }^{9}$. Esta nueva política, concretada en la merced de Gorrevod, inauguró la trata hacia América concebida como negocio a gran escala.

Las factorías africanas de los portugueses eran los indispensables puntos de abastecimiento desde el Tratado de Alcaçovas y era Portugal quien fijaba los mecanismos legales y fiscales para la saca de los esclavos. Por otra parte, el tráfico hacia las Indias españolas era ordenado por la Monarquía castellana mediante la concesión de licencias (al precio de dos ducados por esclavo, salvo exención por merced) para llevar esclavos a las mismas, siendo la Casa de la Contratación de Sevilla el organismo responsable de controlar mediante registro que los traficantes de esclavos no cargasen un número superior al de los concedidos. Era necesario, pues, para hacer realidad la trata atlántica hacia el Caribe español, poner en relación ambos sistemas imperiales, y dado que no estaba permitida a los portugueses la navegación y comercio con las posesiones castellanas en América, resultó imprescindible trasladar los negros hasta Sevilla o los puertos andaluces para desde allí reexpedirlos en barcos autorizados (y tras el oportuno registro en la Casa de la Contratación) hacia América, o bien, que los navíos que partían desde Sevilla o la costa bajoandaluza se dirigiesen a Arguim, Cabo Verde o los ríos de Guinea para cargarlos allí antes de poner rumbo a las Indias. El proceso de cambio de una ruta a otra, mal conocido, se produjo en el periodo 1518-1526 aproximadamente ${ }^{10}$.

Dadas las características de la economía de la Castilla de la época, no resulta extraño que la posesión y gestión de las licencias en esta etapa quedase en manos de un lobby compuesto por hombres de negocios genoveses y castellanos. En efecto, en enero de 1519 Gorrevod vendió sus 4.000 licencias por la suma de 25.000 ducados a una compañía de genoveses, y en los años siguientes serían estos (cuyos apellidos Centurión, Vivaldi y Fornari revelan la importancia de la operación) junto con el burgalés Juan Fernández de Castro quienes explotarían la fabulosa concesión ${ }^{11}$. A fin de materializar los envíos, en 16 de septiembre de 1519 Juan Fernández de Castro, actuando por sí y en representación de Gaspar Centurión y Adán de Vivaldo, contrató con el Rey de Portugal la venta de 4.300 esclavos procedentes del trato de Arguim a precio de 7.500 reais la pieza, debiendo entregarse en 1519-1524; los esclavos

9 Los textos de estas cédulas en AGI, C, leg. 5760, libro 1. Han sido ampliamente glosadas por la historiografía desde SCELLE, 1906, vol. 1: 139-161.

${ }^{10}$ MIRA CABALLOS, 54/201 (Madrid, 1994): 275. ALMEIDA, 7 (Porto, 2004): 13-30.

11 Detalles en OTTE 22 (Münster, 1965): 283-320. OTTE, 2008: 254-261. RAMOS, 81 (San José, 1976): 9. 
tenían que llevarse de Arguim a Lisboa, y desde aquí, en los mismos navíos, a Cádiz o algún otro puerto de Andalucía. Un factor de Juan Fernández de Castro destacado en Lisboa pagaría su importe al tesorero de la Casa de Guinea. Un segundo contrato firmado unos días después modificó el trayecto que debían hacer los esclavos, pues los navíos cargarían los esclavos en Arguim para dirigirse directamente a las Antillas. Sin embargo, estos contratos funcionaron poco más de dos años: entre 1519-1521 el Rey de Portugal vendió a Juan Fernández de Castro 1.420 esclavos, pero los pagos correspondientes no fueron satisfactorios para la administración portuguesa, que acabó suspendiendo las entregas; el burgalés, por su parte, se quejaba de que el monarca luso incumplía los contratos, pues apenas se le dieron 700 esclavos en Arguim, los entregados en Santo Tomé estaban en muy malas condiciones físicas, y los que se llevaron a los puertos de Cádiz y Sanlúcar de Barrameda murieron en gran cantidad poco después de bajar a tierra. Por ello, finalmente, dejó de pagar $^{12}$. Así, la compañía de los 4.000 esclavos negros realizó algunos envíos por su cuenta, pero a partir del conflicto con el Rey de Portugal y la consiguiente dificultad para obtener los esclavos, se dedicó a la reventa especulativa de las licencias durante los siguientes años, lo que encareció su precio (llegando a pagarse hasta 13 ducados por licencia) ${ }^{13}$. Ello entorpeció el tráfico esclavista desde sus primeros años de existencia, y pudo empujar a la Corona a poner un término temporal preciso de ocho años a la concesión de Gorrevod, es decir, hasta $1526^{14}$. Además, la especulación con las licencias entre 1519-1526 impidió una efectiva coordinación entre los abastecedores portugueses y los mercaderes bajoandaluces especializados en el trato atlántico.

En estos primeros años los capitalistas y mercaderes burgaleses (como el judeoconverso Juan Gutiérrez de Bernuy, Alonso de Nebreda, García de Lerma y otros) estuvieron también activos en la trata hacia las Indias de Castilla ${ }^{15}$, frente a unos andaluces que no dejaron de experimentar dificultades para penetrar en la misma. De hecho, los mercaderes de la Baja Andalucía tuvieron necesariamente que adquirir las licencias de manos de genoveses y burgaleses. Evidentemente, el papel destacado que los burgaleses juegan en estos años tiene que ver con la posición que el capitalista Juan Fernández de Castro ocupaba en el negocio de la trata. Este era miembro de un importante y rico linaje de la oligarquía burgalesa ${ }^{16}$ y se había avecindado en Sevilla, desde 711, n. 9.

${ }^{12}$ Los textos de los contratos y el pleito de comienzos de la década de 1530, en: AGI, J,

${ }^{13}$ RAMOS, 81 (San José, 1976): 9-10. GARCÍA FUENTES, 19 (Böhlau, 1982): 22. FERNÁNDEZ CHAVES y PÉREZ GARCÍA, 25 (Madrid, 2012): 206-207.

${ }^{14}$ RAMOS, 81 (San José, 1976): 9.

15 AGI, C, leg. 5760, libro 1. También MARTín ACOSTA, 73/1 (Burgos, 1994): 46.

${ }^{16}$ Sobre la familia burgalesa de los Castro, especializada en las finanzas, los seguros marítimos y la exportación de lana al norte de Europa, la importación de paños a Castilla, y 
donde dirigía sus negocios. Junto con Gaspar Centurión era «gobernador de la compañía de los 4.000 esclavos desde 1519 , y desde diciembre de ese año Juan Fernández de Castro disponía de la cuarta parte de las licencias que restaban por usar (con la capacidad para enviar en exclusiva los esclavos hacia las islas de Cuba y San Juan); Centurión se reservaba las otras tres cuartas partes de las licencias, que deberían emplearse para llevar esclavos a Santo Domingo y las otras islas ${ }^{17}$. Es ahora cuando se ponen las bases para una destacada participación burgalesa en la trata negrera hacia las Indias durante las décadas siguientes.

El interés de los burgaleses en la trata es comprensible si recordamos que en el último tercio del siglo XV ya habían llevado sus barcos y negocios hasta Santiago de Cabo Verde, San Jorge de la Mina o los ríos de Guinea, estableciéndose sólidamente en Lisboa, plaza desde donde jugaron una función de transmisión de los distintos productos de las posesiones portuguesas (azúcar de Madeira, pastel de las Azores, y un poco más tarde pimienta de la India) hacia el norte de Europa en los tiempos del cambio de siglo ${ }^{18}$. Sus compras masivas de especias en la «Casa da India» (para reexportar a Flandes, fundamentalmente), su control de los seguros marítimos, sus préstamos a los monarcas portugueses y su contribución a la financiación de las flotas de la India, les proporcionaron una sólida posición en Lisboa al menos hasta mediados del Quinientos ${ }^{19}$. Dado que desde los primeros años del siglo XVI ocupaban un importante lugar en la economía del primer Caribe español ${ }^{20}$ y en la producción y comercialización del azúcar de las Canarias ${ }^{21}$, resulta comprensible que, en la coyuntura política favorable que supuso para ellos la llegada de Carlos I a España con su corte flamenca, los burgaleses apostasen con fuerza por introducirse en la naciente trata negrera organizada hacia las Indias de Castilla.

A pesar de los problemas derivados específicamente de la gestión de la licencia de Gorrevod ${ }^{22}$, y de que en 1520-1521 los burgaleses experimentaban dificultades para vender esclavos en Cuba (algunos del propio Juan Fernán-

con variados intereses en el Atlántico y en el Mediterráneo: OTTE, 18/2 (México, 1968); CAUNEDO DEL POTRO, 1986. Emparentaron con la importante familia judeoconversa burgalesa de los Maluenda.

17 AGI, C, leg. 5760, libro 1. Respecto a Yucatán y las nuevas tierras que se descubriesen, Castro y Centurion tendrían, llegado el caso, derecho a introducir el mismo número de esclavos.

18 RAMOS, 1992: 131-157. CASADO ALONSO, 2003a: 128-129. CASADO ALONSO, $2003 b$.

${ }^{19}$ CASADO ALONSO, 2003a: 124-128. GODINHO, 1991, vol. 3: 190-214.

20 OTTE, 18/2 (México, 1968): 108-144. MARTÍN ACOSTA, 73/1 (Burgos, 1994): 39-52.

${ }^{21}$ LOBO, 36 (Madrid - Las Palmas, 1990).

${ }^{22}$ OTTE, 2008: 254-258. 
dez de Castro, y otros de Alonso de Nebreda y Hernando de Castro, destacado este último allí) a causa de la escasez de oro existente en la isla ${ }^{23}$, en los años siguientes Fernández de Castro supo aprovechar sus licencias a través de lucrativas operaciones de reventa en los que el precio de éstas multiplicó en el mercado el valor oficial originario, como veremos. Juan Fernández de Castro actuaba a un nivel especulativo y, como los genoveses, generaba un negocio financiero paralelo a la propia trata pero directamente derivado de ella. Sus ventas de licencias del paquete de Gorrevod nos conducen a los mercaderes protagonistas de la materialización del tráfico esclavista hacia las Indias de Castilla. Entre éstos juega un papel crucial en la historia de la primitiva trata negrera hacias las Indias de Castilla una familia judeoconversa de origen andaluz, los Torres.

El historiográficamente confuso origen de los Torres ${ }^{24}$ ha sido esclarecido por María Teresa López Beltrán ${ }^{25}$. Se trata de una familia judeoconversa, probablemente de origen cordobés (uno de sus miembros, Juan Martínez de Santa Cruz, médico de la ciudad de Córdoba, fue condenado a la hoguera por la Inquisición en 1497), establecida en Málaga a partir de 1493 bajo la égida de Fernando de Córdoba ( $†$ 1523), padre de una numerosa saga de ricos hombres de negocios (Alonso, Diego, Gaspar de Torres, hijos de su primera mujer; y Melchor de Torres, hijo de su segunda esposa) y destacados eclesiásticos ${ }^{26}$. En Málaga, Fernando de Córdoba se convirtió, junto con el también converso Rodrigo Álvarez de Madrid, en cabeza de un poderoso grupo de arrendadores judeoconversos de rentas reales y eclesiásticas en el Reino de Granada. El importante papel alcanzado en el seno de la élite financiera dedicada al arrendamiento de rentas en la Corona de Castilla explica tanto que en 1503 su hijo Diego de Torres casase con doña Elvira Suárez, hija del riquísimo judeoconverso sevillano Pedro del Alcázar, uno de los más importantes arrendadores de rentas de Castilla, como que en 1519 Fernando de Córdoba se contase entre uno de los ocho arrendadores de la Postura General de Barcelona que aportaron casi un millón de ducados al erario público a cambio de todos los arrendamientos de la Hacienda real castellana por un periodo de seis años (Fernando de Córdoba aportó junto con Luis Núñez de Andújar 48.861 ducados, el 4'98\% del total; Rodrigo Álvarez de Madrid otros 80.019 ducados, lo que suponía un 8'18\%; y Pedro del Alcázar la friolera de 251.040 ducados, el $25^{\prime} 63 \%{ }^{27}$. Fer-

23 OTTE, 18/2 (México, 1968): 136-137.

${ }^{24}$ MATEUS VENTURA, 1999: 39 y otros como FONSECA, 2010: 166, los han considerado erróneamente portugueses; GODINHO, 1991, vol. 4: 177 dice que son burgaleses, y en vol. III: 197-198 y 203, los confunde con los burgaleses De la Torre.

${ }^{25}$ LÓPEZ BELTRÁN, 24 (Granada, 2012): 33-72.

26 SOTO ARTUÑEDO, 2002.

${ }^{27}$ CARRETERO, 2011: 116-117. 
nando de Córdoba fue un hombre muy rico: en 1507 su patrimonio ascendía a 10.000 ducados, y ello a pesar de su detención por la Inquisición entre 15051508 y el secuestro de sus bienes. Nos interesan también aquí sus actividades mercantiles. Fernando de Córdoba sostuvo activas relaciones comerciales con el norte de África y con los mercados flamencos e ingleses del Norte de Europa, a los que exportaba fruta pasa del Reino de Granada. Especial relevancia tiene su vinculación con Portugal: Fernando de Córdoba mantuvo continuos negocios con mercaderes portugueses que traían a Málaga barcos con esclavos negros, y que luego cargaban trigo en Málaga para llevarlo a Portugal, aportando al reino vecino un producto estratégico del que era crónicamente deficitario ${ }^{28}$. Al menos entre 1497 y 1519 se documenta relación de Fernando de Córdoba con carabelas portuguesas que traen esclavos negros a la costa del Reino de Granada; en esta actividad negrera fue secundado por su hijo Diego de Torres, quien en 1516 vendió no menos de 63 negros bozales de Guinea a distintos vecinos de Málaga; también otros socios judeoconversos de Fernando de Córdoba, como Rodrigo Álvarez de Madrid, aparecen implicados en la importación de numerosos esclavos negros comprados a mercaderes portugueses que operan en Málaga ${ }^{29}$. Entre 1515 y 1518 conocemos diferentes ventas de trigo andaluz de los hermanos Alonso y Diego de Torres al factor portugués de Andalucía ${ }^{30}$. La importancia de los intereses económicos de Fernando de Córdoba en Portugal podría explicar que uno de sus hermanos, Alonso de Benavente, fuese «persona que sabe y entiende la letra portuguesa».

Desconocemos los pasos precisos seguidos por los Córdoba-Torres para alcanzar una posición económica prominente en Lisboa. En 1515 Diego de Torres ya figuraba como vecino de Lisboa, si bien durante los años siguientes vivió a caballo entre la capital lusa y Málaga, comerciando con trigo, fruta pasa y esclavos entre Flandes, Portugal, Málaga y Valencia, al menos, y asociándose para ello tanto con mercaderes castellanos como portugueses ${ }^{31}$. Diego de Torres también realiza importantes entregas de plata a la Casa de la Moneda de Lisboa al menos desde 1520 (y hasta 1543, más de 7.800 marcos de plata), además de comprar, en 1522 por ejemplo, pimienta y jengibre en la Casa da India de Lisboa; por su parte, Alonso de Torres, otro de los hijos de Fernando de Córdoba, hace en 1517-1518 sustanciales entregas de plata (más

${ }^{28}$ LÓPEZ BELTRÁN, 24 (Granada, 2012): 66-67; LÓPEZ BELTRÁN, GONZÁLEZ ARÉVALO, 24 (Málaga, 2002): 334-337.

${ }^{29}$ GONZÁLEZ ARÉVALO, 2006: 232-236.

${ }^{30}$ LÓPEZ BELTRÁN, GONZÁLEZ ARÉVALO, 24 (Madrid, 2002): 336 y 331. CORTE-REAL, 1967: 172-173

${ }^{31}$ LÓPEZ BELTRÁN, GONZÁLEZ ARÉVALO, 24 (Málaga, 2002): 336-337. 
de 2.400 marcos de plata) a la Casa de la Moneda de la capital portuguesa ${ }^{32}$. Estas actividades con metales preciosos las realizarían los hermanos Torres y otros mercaderes castellanos en el marco de las operaciones de financiación de la flota de la India y las actividades de la Casa da India ${ }^{33}$. Diego de Torres también contribuyó a la financiación de la factoría portuguesa de Andalucía, girando letras de cambio desde Lisboa para cobrar en Sevilla por el factor del Rey de Portugal (conocemos cinco letras entre 1524 y 1527, una de ellas de 1.000 cruzados); al menos una parte de este dinero serviría para la compra del trigo que después se reexportaría hacia Portugal y las plazas norteafricanas ${ }^{34}$. Al menos desde 1522 tanto Diego como Alonso de Torres reciben distintos privilegios del Rey de Portugal, y en 1525 ambos recibieron el de ciudadano de Lisboa ${ }^{35}$.

Es evidente el interés de los Torres por los lucrativos productos traídos a Europa gracias a la apertura de las rutas oceánicas. Según la hipótesis de Zelinda Cohen, Alonso de Torres habría podido llegar a desempeñar un importante puesto oficial en los órganos centrales de fiscalización del comercio de ultramar como proveedor de los «almazéns de Guiné e Índias» al menos desde $1528^{36}$. Diego de Torres, por su parte, se habría acabado estableciendo en Lisboa hacia 1525-1526, formando en 1528 una compañía con el también judeoconverso andaluz Gonzalo de Baeza para comerciar con el pastel de las Azores $^{37}$. Para entonces los Torres ocupaban un lugar clave en Lisboa y en la trata negrera, actuando desde el lado portugués del negocio. Es significativo que uno de los tres testigos y fiadores que en 1519 aparecen en el antes comentado contrato de compra al rey de Portugal de 4.300 esclavos por Juan Fernández de Castro, Gaspar Centurión y Adán Vivaldo sea precisamente Alonso de Torres, junto con Andrés de Silvera y Luis Ytalián; también es llamativa la presencia de un miembro de la familia genovesa de los Ytalián, que desde la década de 1490 y primeros años del Quinientos había jugado junto con los Centurión un destacado papel en la exportación del trigo castellano desde el puerto de Málaga hacia el Levante peninsular, Italia y Portugal, gozando para ello de privilegios reales cuya obtención se ha de relacionar con los importantes créditos que estos negociantes italianos hacían a la Corona española ${ }^{38}$. Todo ello revela la confianza que despertaban los Torres en la

32 GODINHO, 1991, vol. 3: 197-198.

33 CASADO ALONSO, 2003a: 125-126.

${ }^{34}$ CORTE-REAL, 1967: 57-60.

${ }^{35}$ COTTA DO AMARAL, 1965: 53-54.

${ }^{36}$ COHEN, 53 (Lisboa, 1994): 341.

${ }^{37}$ LÓPEZ BELTRÁN, 24 (Granada, 2012): 70-71.

${ }^{38}$ LÓPEZ DE COCA, 7 (Sevilla, 1980): 108, 111-113, 119-123. Este Luis Ytalián destacado en Portugal compraba pimienta a la Casa da India en esta época (GODINHO, 1991, vol. 3: 197) 
Corte portuguesa, así como su pronta vinculación con la trata negrera, e insiste en la idea de que la función estratégica de Málaga para la Corona portuguesa contribuyó al creciente ascendiente de los Torres en los medios políticos y económicos portugueses ${ }^{39}$. Además, la presencia de miembros de la familia Córdoba-Torres en el cabildo malagueño contribuía a defender los intereses lusos en lo relacionado con la exportación del cereal y la actividad de la factoría portuguesa de Andalucía ${ }^{40}$.

Todo esto nos permite comprender que fuese a los Torres a quienes Juan Fernández de Castro traspasase gran número de licencias. En 1523 Juan Fernández de Castro vendió a Diego y Alonso de Torres («estantes en Lisboa») y a Juan de Polanco Maluenda (burgalés avecindado en Sevilla y que actuaba también en nombre de los Torres) doscientas licencias de la concesión de Gorrevod para llevar esclavos negros a Cuba y Puerto Rico ${ }^{41}$. Pero poco después esta operación fue anulada, devolviéndole Polanco las licencias un mes más tarde ${ }^{42}$. Otro traspaso de Juan Fernández de Castro de un centenar de licencias al jurado Francisco de la Corona (hermano de Juan Díaz de Gibraleón ${ }^{43}$ ) también se canceló a fines de ese mismo año ${ }^{44}$, poniendo de manifiesto las dificultades que entre 1523-1525 atravesaba la trata negrera hacia las Indias de Castilla.

Hay que esperar a 1526 para que Juan Fernández de Castro realice su mayor operación en el marco de la trata negrera, apareciendo de nuevo los Torres; ésta tenía un carácter doble y movilizaba grandes capitales. Primero contrató con el Rey de Portugal la compra de 750 esclavos que le serían entregados en la isla de Santiago de Cabo Verde, a razón de 150 individuos por año durante cinco años a partir del mismo 1526. Después firmó una capitulación con Diego de Torres, residente en Lisboa (aunque para esta ocasión se desplazó hasta Sevilla), con el objeto de realizar conjuntamente el negocio: para empezar, Diego de Torres se hacía con la quinta parte del contrato firmado con el Rey de Portugal (es decir, lo relativo a 150 esclavos); además, Juan Fernández de Castro le traspasó las 287 licencias que le quedaban de Gorrevod (mediante venta a precio de diez ducados por cada licencia) y se comprometió a traspasarle todas las que pudiera conseguir de dicha merced, dado que eran necesarias muchas más para enviar los 750 esclavos a América; asimismo, Diego de Torres actuaría en Lisboa ante los oficiales de la Casa de la Mina para recibir y pagar los esclavos, encargándose asimismo de fletar

\footnotetext{
${ }^{39}$ GODINHO, 1991, vol. 3: 269-280.

40 Documentos en este sentido en BEJARANO, 1941.

${ }^{41}$ AHPSe, PNS, leg. 3254, f. 91v-92r. 19-II-1523.

${ }_{42}$ AGI, C, leg. 5760, libro 1. 15-III-1523.

${ }^{43}$ GIL, 2001, vol. 3: 547.

${ }^{44}$ AGI, C, leg. 5760, libro 1. 9-XII-1523.
} 
o comprar un navío (o más) junto con todo lo necesario (vituallas, seguro de la mar, seguro de vida de los esclavos, y personal que iría con los esclavos) para el viaje y venta en las Indias ${ }^{45}$.

Pocos meses antes los genoveses (los Spínola o Espíndola) habían comprado al Rey de Portugal 600 esclavos negros que se les debían entregar en la isla de Santo Tomé, los cuales se enviarían a las Indias castellanas utilizando las licencias de la merced de Gorrevod que todavía tenían Agustín de Bivaldo y Domingo de Forne; en mayo de 1526 los genoveses ultimaban en Sevilla, Málaga y Lisboa los preparativos de su negocio, y poco después comenzaron a enviar los esclavos ${ }^{46}$. En 1526, después de varios años en que los envíos de esclavos habían sido escasísimos, la competencia en la trata negrera se volvía feroz. Por ello Juan Fernández de Castro se esforzó por hacer efectivo su semi-monopolio dando instrucciones al vizcaíno Sancho de Arteaga, a la sazón en Sanlúcar de Barrameda, para que comprobase personalmente que los barcos que iban a las Indias no llevaban esclavos sin licencia; se trataba de un control que el mismo rey le había autorizado a realizar ${ }^{47}$. Y cuando tuvo noticia de que un tal García del Castillo había llevado esclavos desde Lisboa a la isla de San Juan sin licencia para ello, Fernández de Castro se movió para querellarse contra él y reclamar la posesión de tales esclavos en virtud de la provisión real de que disfrutaba y las sentencias dadas a su favor ${ }^{48}$. No obstante, una vez desaparecida a partir de 1527 su posición de ventaja en el negocio del tráfico de esclavos, Juan Fernández de Castro se retiró de él ${ }^{49}$ y centró su interés en la explotación monopolística del palo brasil de las Indias, aunque sin éxito ${ }^{50}$.

Desde estos momentos, otro burgalés, Juan de la Torre, parece sustituirlo en la dirección de la participación burgalesa en la trata negrera: de hecho ya se había hecho con algunos lotes de licencias desde $1526^{51}$, compartía con

${ }^{45}$ AHPSe, PNS, leg. 3265, f. 564v-565r, 566r-v, 567r-v, 587r-588v. Documentos de 13/X/1526. El texto íntegro del contrato de 10-I-1526 entre Juan Fernández de Castro y el Rey de Portugal, en AGI, J, 711, n. 9.

${ }^{46}$ Catálogo, 2004, vol. 9: docs. 74, 90, 91, 92, 95, 96. Este consorcio genovés envió, al menos, con el portugués Cristóbal Rodríguez, un cargamento de 300 esclavos negros ese mismo año de 1526 desde Santo Tomé hasta el puerto de Santo Domingo en la isla Española (Catálogo, 1937, vol. 5: doc. 1267).

47 AHPSe, PNS, leg. 3265, f, 465v. 18-IX-1526.

48 AHPSe, PNS, leg. 3265, f. 565v. 13-X-1526.

49 Así lo indican los registros de la Casa de la Contratación (AGI, C, leg. 5760, libro 1).

${ }^{50}$ LORENZO SANZ, 1979, vol. 1: 598.

${ }^{51}$ De la Torre se benefició del traspaso de la cédula de veinte licencias concedida en 5/V/1526 a María de Vilda, costurera de la Reina; y de otras sesenta procedentes de una cédula de 15/XI/1527 por 200 esclavos obtenida por el doctor Beltrán, del Consejo de Indias, y que este había traspasado previamente y de forma íntegra a Luis Fernández de Alfaro, del que pasaron las dichas sesenta licencias al burgalés (AGI, C, leg. 5760, libro 1). 
Juan Fernández de Castro factores en San Juan de Puerto Rico para vender allí sus esclavos ${ }^{52}$, y disponía en Lisboa de diversos contactos que le permitieron seguir organizando embarques de esclavos hacia las Indias ${ }^{53}$. La continuación de la actividad negrera por Juan de la Torre fue también posible porque consiguió que en agosto de 1528 Agustín de Vivaldo le traspasase 150 licencias del paquete de Gorrevod, y en 1 de julio de 1532 obtuvó una cédula real que le permitía enviar los 75 esclavos que le restaban por usar de ese traspaso «a causa de no los aver allado a conprar e por otras causas e ynpedimen-

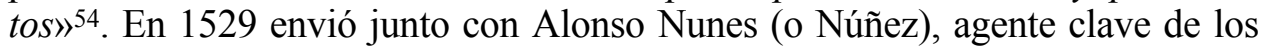
portugueses en Sevilla, como enseguida veremos, cien piezas de esclavos con rumbo a Puerto Rico y Santo Domingo ${ }^{55}$, si bien dos años más tarde Nunes reclamaba parte de lo que le correspondía por las dos terceras partes del cargamento humano ${ }^{56}$. Por supuesto, durante estos años De la Torre alternó los envíos de esclavos con el beneficioso negocio de la reventa de las licencias.

\section{LA IRRUPCIÓN DE LOS JUDEOCONVERSOS ANDALUCES EN LA TRATA NEGRE- RA, 1527-CA. 1540}

En 1527, con el fin del oligopolio genovés y burgalés en materia de licencias, comenzó un proceso por el que las grandes familias de mercaderes judeoconversos sevillanos y andaluces penetraron con ímpetu creciente en el negocio negrero atlántico. En los años previos sólo habían podido participar en la trata mediante envíos atomizados tras la compra de las necesarias licencias a genoveses y burgaleses: así el importante mercader sevillano Luis Fernández de Alfaro apenas había podido enviar trece esclavos negros entre 1521 y 1524; Rodrigo de Gibraleón sólo cargó esclavos en 1521, catorce piezas en tres naos distintas; los hermanos Hernando de Jerez y Juan Núñez únicamente enviaron entre 1519-1522 cuatro esclavos negros cada uno a Santo Domingo; Antón Caballero, vecino de Sanlúcar, sólo remitió siete esclavos a las Indias, entre 1519-1520; Alonso Caballero, por su parte, se hizo con una licencia para seis esclavos, y los cargó entre 1519-1520; muchos otros, como Gómez de Prado o Andrés de la Barrera, solo enviaron un esclavo (en estos casos en 1521 y 1519 respectivamente). También se hicieron con algunas licencias procedentes de alguna otra merced real (como la de 400 licencias concedida a don Jorge de Portugal en 1518), en virtud de la cual Rodrigo de Gibraleón y

${ }^{52}$ Catálogo, 1986, vol. 6: doc. 405. 15/V/1528.

53 Catálogo, 1986, vol. 6: doc. 692. Catálogo, 2004, vol. 9: doc. 1042.

${ }^{54}$ AGI, C, leg. 5760, libro 1. En 1527 Melchor de Carrión le traspasó otras 17 licencias.

${ }^{55}$ Catálogo, 1986, vol. 6: doc. 929.

${ }^{56}$ AHPSe, PNS, leg. 40, f. 666r-v. 4/IX/1531. 
Diego de Sevilla cargaron otros cuatro esclavos en 1518 y Antón Caballero otros dos, pero poco más ${ }^{57}$.

Al terminar el oligopolio genovés y burgalés la Corona comenzó a vender y conceder nuevos paquetes de licencias. Sin embargo, un análisis detallado de los beneficiarios de las licencias concedidas entre 1526 y 1531 revela claramente que la Corona no deseaba que floreciese una trata negrera guiada por la iniciativa de mercaderes, pues las concedidas a estos son escasísimas (como las 30 licencias vendidas a Sancho Ortiz de Urrutia). Como había hecho desde 1518, la Monarquía continuó utilizando las licencias para premiar a miembros de la Corte y del aparato burocrático central (que suelen obtener las mercedes más importantes, como Francisco de los Cobos, Diego de Zárate, Alonso Idiáquez, el Dr. Beltrán, etc), beneficiar al personal de gobierno que enviaba a las Indias (regidores, oidores, gobernadores, tesoreros, un deán y un obispo, ... de los nuevos órganos creados en ultramar), y ayudar a algunos conquistadores y pobladores a quienes se permitía pasar unos pocos esclavos para su servicio personal o determinadas necesidades laborales. De entre el medio centenar de beneficiarios de licencias del periodo 1526-1531, tan sólo hay otros dos individuos con un perfil mercantil claro, pero que si consiguieron lucrar sendas licencias fue también porque al mismo tiempo detentaban cargos públicos: el burgalés García de Lerma, obtuvo veinte licencias en 1528, como gobernador de la provincia de Santa Marta; y el andaluz Diego Caballero, contador de la isla Española, con importantes inversiones en ingenios de azúcar en la misma, y que lucró varias cédulas reales que le otorgaban licencias entre 1527 y 152958 .

El modelo de gestión que la Corona deseaba para la trata negrera seguía siendo el de una gran concesión en régimen de cuasimonopolio. Así, el rey firmó un nuevo asiento (Burgos, 12 de febrero de 1528) con los alemanes Enrique Ehinguer y Geronimo Sayler, agentes de los Welser en España. Estos podrían llevar cincuenta maestros mineros alemanes a las Indias para extraer oro e introducir 4.000 esclavos negros en los siguientes cuatro años (al precio el paquete de 20.000 ducados) en régimen de cuasiexclusividad (las licencias previamente concedidas seguirían teniendo efecto, y los que fueren como pobladores y conquistadores a las Indias podrían llevar «cada uno dellos dos esclavos y no más») ${ }^{59}$. Resulta claro que para la Corona la trata era todavía una actividad secundaria, y que sus prioridades se centraban en las minas de metales preciosos y en la cesión y arrendamiento de grandes fuentes de ingresos a potentes grupos financieros a cambio de préstamos y cantidades fijas de dinero. Para los alemanes, todo esto formaba parte de un planteamiento gene-

57 AGI, C, leg. 5760, libro 1.

58 AGI, C, leg. 5760, libro 1.

${ }^{59} \mathrm{El}$ texto del asiento en AGS, CJH, 10-109. 
ral de penetración en América que había comenzado en 1526 con la instalación por parte de los Welser de una factoría en Santo Domingo, y que continuó al año siguiente mediante un acuerdo con el acaudalado burgalés García de Lerma, miembro de una familia con amplia experiencia en el Caribe, y que se convertiría en gobernador de Santa Marta, al tiempo que debía funcionar como vector de la penetración alemana ${ }^{60}$.

El asiento de Ehinger y Sayler constriñó nuevamente la trata hacia las Indias. La Corona cumplió los términos del asiento, de forma que las nuevas mercedes concedidas lo fueron a pobladores y sólo por dos licencias, o bien a miembros del entorno cortesano y político del gobierno central (tales como Rodrigo de la Corte, del Consejo de Indias; el capellán real Juan de Silveira; doña Juana de Silveira; los secretarios Diego de Zárate y Alonso Idiáquez; Juan de Samano, responsable del cobro en la Corte del valor de las licencias; o la Condesa de Faro) a quienes los documentos de concesión de sus interesantes mercedes (todas ellas de cien licencias) recordaban puntualmente que sólo podrían utilizarse tras la expiración de la validez del asiento de los alemanes $^{61}$. En 1529 Ehinger y Sayler consiguieron una nueva cédula para introducir otros 800 esclavos negros en Venezuela ${ }^{62}$. No obstante, la empresa de los alemanes tropezó con dificultades, ya conocidas por la historiografía. Un indicio de ello es que en 1534 consiguiesen que la concesión de 25 de julio de 1529 para introducir 800 esclavos en Venezuela se hiciese extensiva a cualquier parte de las Indias (lo que revela que no la habían explotado), y que durante los años siguientes no enviasen esclavos sino que se limitasen a revender dichas licencias tanto en grandes paquetes (150 licencias pasaron a Alonso Caballero, 350 al jurado Alonso Román y Juan de Valladolid, y otras 100 a Juan Núñez) como en pequeños lotes ${ }^{63}$.

Los problemas de los alemanes y la creciente capacidad económica de la élite mercantil judeoconversa andaluza que se proyectaba en el Atlántico permitieron una penetración imparable de ésta en la trata negrera entre las décadas de 1520 y 1530. Ello fue posible gracias a que consiguieron adquirir numerosas licencias en el mercado secundario: así, se hicieron con buena parte de los restos de licencias sin explotar de las mercedes de 1518, como Luis Fernández de Alfaro, el cual en 1528-1532 utilizó 180 licencias de las del marqués de Astorga para enviar esclavos; y se dedicaron a la compra de lotes de distintos beneficiarios de licencias: por ejemplo, el mismo Luis Fernández de Alfaro se hizo con las 200 licencias concedidas en 1527 al Dr. Beltrán, del

${ }^{60}$ RAMOS, 81 (San José, 1976): 19 y 31-35. MARTÍN ACOSTA, 73/1 (Burgos, 1994): $51-52$.

${ }^{61}$ AGI, C, leg. 5760.

62 AGI, C, leg. 5760, libro 2.

${ }^{63}$ AGI, C, leg. 5760, libro 2.

Hispania, 2016, vol. LXXVI, nº. 253, mayo-agosto, págs. 385-414, ISSN: 0018-2141, e-ISSN: 1988-8368, doi: 10.3989/hispania.2016.012 
Consejo de Indias, de las que a su vez traspasó 60 al burgalés Juan de la To$\mathrm{rre}^{64}$. Compraron licencias incluso a los propios alemanes ${ }^{65}$.

Los Caballero consiguieron sus propias licencias para enviar los negros que precisaban gracias al cargo que Diego disfrutaba de contador de La Española, al tiempo que supieron adquirir otras en el mercado secundario de licencias. Diego Caballero ganó varias cédulas: en 1 de junio de 1527 para 50 esclavos negros; en 5 de julio de 1527 para enviar a dicha isla un esclavo suyo berberisco loro y ladino; en 14 de junio de 1527 para pasar seis esclavas suyas (probablemente berberiscas) y un esclavo muchacho llamado Perico para servicio de su persona y casa; y de nuevo en 4 de junio de 1529 y con el mismo fin para pasar a La Española otro esclavo y otra esclava; en 9 de agosto de 1529, finalmente, para 30 esclavos negros. Todos estos esclavos y esclavas, 90 en total, los envió a las Indias entre 1527 y 1531 . Además, Diego Caballero compró en 1527 a Pedro Serrano las 25 licencias que este acababa de obtener (cédula de 20 de julio de 1527) para enviar esclavos a La Española, encargándose su hermano Alonso Caballero de remitirlos entre 1527-1528. Alonso también se valió de 50 de las licencias que había obtenido en 1529 Rodrigo de la Corte, del Consejo de Indias, para enviar otros 50 negros en $1530^{66}$.

A partir de 1530 los hermanos Hernando de Jerez y Juan Núñez comenzaron también a hacerse con grandes lotes de licencias procedentes de los restos sin explotar de las grandes licencias del periodo anterior, usándolas para enviar esclavos a las Indias: en marzo de 1530 registraron 60 esclavos negros tras obtener la correspondiente autorización (por venta) de Agustín de Vivaldo, quien en ese momento gestionaba lo que quedaba de la licencia de Gorre$\operatorname{vod}^{67}$; otras 60 licencias obtuvieron en 1530 del resto de la cédula de 27 de septiembre de 1518 que concedió en su día 400 licencias al marqués de Astorga y que por esta época gestionaban Agustín Vivaldo y el jurado toledano Hernán Vázquez ${ }^{68}$ : todas ellas fueron aprovechadas para enviar esclavos en 1530-153169. Por estos años, dado que la vigencia del asiento de Ehinger y Sayler bloqueaba la obtención de licencias directamente de la Corona, comenzaron a comprar pequeños lotes de licencias a beneficiarios menores ${ }^{70}$, además de aprovechar la brecha contenida en el asiento que aprobaba la concesión a los pobladores de dos licencias para llevar negros para su servicio ${ }^{71}$.

${ }^{64}$ AGI, C, leg. 5760, libro 1.

65 Catálogo, 1986, vol. 6: doc. 1116. 14/III/1530.

66 Todo lo anterior en AGI, C, leg. 5760, libro 1.

${ }^{67}$ AGI, C, leg. 5760, libro 1.

68 Catálogo, 2004, vol. 9: doc. 1427.

${ }^{69}$ AGI, C, leg. 5760, libro 1.

${ }^{70}$ Catálogo, 2006, vol. 10: doc 185. 9/VI/1531.

${ }^{71}$ Cómo la cédula que daba licencia a Juan Núñez para pasar a Indias dos esclavos negros para servicio personal (AGI, IG, 422, L. 15, f. 17v. 11/III/1531), o aquella otra para pasar a Indias un esclavo y una esclava negros (AGI, IG, 422, L. 15, f. 115r. 31/I/1531). 
Hacia 1530-1531 las grandes familias judeoconversas andaluzas ya habían establecido un mecanismo de conexión con el sistema esclavista portugués, poniendo las bases para un predominio creciente en el sector. Para ello fueron clave, de nuevo, los Torres, especialmente Alonso de Torres. Entre 1529 y 1531 Alonso de Torres obtuvo en unas condiciones extremadamente ventajosas tanto el arrendamiento del cobro de los cuartos y veintenas de Santiago de Cabo Verde sobre las importaciones de Guinea como la explotación de los Ríos de Guinea con el derecho a «factorizarlos», lo que suponía la suspensión temporal del factor real en Santiago y su sustitución por otro nombrado por el propio contratador. Ello otorgaba al contratador un enorme poder fáctico en esas regiones. En 1531 aparece también como quien "feitorizava» la isla de Santo Tomé, confluyendo en él sus intereses económicos personales con la condición de funcionario de la Corona portuguesa encargado de la defensa de los de ésta. Finalizado el periodo en que tenía derecho a los cuartos y veintenas de Santiago, se mantuvo como «feitor dos tratos de Guiné» por el rey, sin abandonar por ello un intenso trato mercantil entre Flandes, Portugal, Cabo Verde, la costa de Guinea, Santo Tomé y las Antillas. Para ello disponía de una serie de agentes en las zonas africanas ${ }^{72}$ y en otras partes, como Sevilla. En esta época, quienes se convertían en arrendadores conseguían su contrato tras una puja en Lisboa, accediendo con ello a una serie de privilegios y ventajas: entre otras, adquirían la condición de vecino de Santiago, lo que les habilitaba para participar en los tratos de Guinea. Alonso de Torres alcanzó además la condición de «cavaleiro fidalgo» de la Casa del Rey de Portugal, una nobleza que, a pesar de todo, denotaba más su cercanía con el carácter mercantil de los demás «rendeiros» que con la propia hidalguía de linaje ${ }^{73}$. En diversos documentos sevillanos se le llama también «factor del Rey de Portugal», «factor del Rey de Portugal en los Ríos de Guinea» o «Comendador de la Orden de Cristo». De su poder económico habla el que por sus arrendamientos del periodo 1529-1531 pagase anualmente a la Corona lusa cuatro millones de reais $^{74}$. Alonso de Torres continuó ejerciendo en los años siguientes un papel determinante en el comercio de esclavos y diferentes productos africanos. Además, entre 1536 y 1541 (ó 1542) volvió a hacerse con el trato de los Ríos de Guinea ${ }^{75}$. Las palabras de Zelinda Cohen no son en absoluto exageradas: «Foi, sem dúvida, entre todos os rendeiros de Cabo Verde até 1560 o maior e mais poderoso mercador» ${ }^{76}$. De la progresión imparable

72 COHEN, 53 (Lisboa, 1994): 341-342, 355, 357-358.

${ }^{73}$ COHEN, 53 (Lisboa, 1994): 333, 346.

${ }^{74}$ COHEN, 53 (Lisboa, 1994): 338; CABRAL, FERRAZ TORRÃO, 54-55 (Lisboa, 1996): 48.

75 COHEN, 53 (Lisboa, 1994): 342; FERRAZ TORRÃO, 2013: 95-97.

${ }^{76}$ COHEN, 53 (Lisboa, 1994): 341. 
de Alonso de Torres en el Atlántico portugués habla finalmente el hecho de que en 1549 obtuviera de João III una carta de sesmaría de tierras en Bahía 77 , en Brasil, en un momento fundacional tras el fracaso del primer intento luso de establecimiento en esa región.

Alonso de Torres será quien proporcione desde comienzos de la década de 1530 la mayor parte de los grandes cargamentos de esclavos requeridos por los mercaderes conversos andaluces para las Indias de Castilla. Para ello disponía de un agente en Sevilla, el mercader Alfonso Núñez (o Nunes en algunos documentos ${ }^{78}$, revelando su origen luso), vecino de Sevilla, que negociaba personalmente los contratos con los andaluces. Este Alfonso Núñez fue en estos años uno de los principales intermediarios que conectaba la trata portuguesa con la castellana a partir de Sevilla. El número e importancia de sus operaciones así lo prueban. En 1530, actuando en nombre de Alonso de Torres, Alfonso Núñez se concertó con el mercader Sancho Caballero, vecino de Sevilla, para cargar cien esclavos en los Ríos de Guinea para las Indias de Castilla; el trato sólo se cerró tras la ratificación de Alonso de Torres, que Alonso Núñez trajo y enseñó a Caballero el siete de enero de 1531. La importancia de la figura de Torres se pone de manifiesto en el hecho de que el escribano se refiera a él como «señor» y «factor del serenísimo e muy poderoso señor Rey de Portugal $\gg^{79}$. Pocos días después el mercader sevillano Juan de la Barrera se obligaba a pagar a Alonso Nunes 815 ducados como pago de los veinte esclavos negros que este se comprometía a proporcionar en Santiago de Cabo Verde al maestre Pedro de Boria, que debía recogerlos en su nao «San Nicolás» y llevarlos hasta la isla de San Juan; por supuesto, eran los factores de Alonso de Torres en Cabo Verde quienes debían entregar los esclavos ${ }^{80}$. En marzo de 1531 Alfonso Núñez vendió en Sevilla (de nuevo en nombre de Al[f]onso de Torres) a Luis Fernández de Alfaro y su hijo Juan de Alfaro otro cargamento de cien esclavos negros de Guinea y Cabo Verde, comprometiéndose a enviar un barco desde Lisboa a esos puertos para cargarlos y transportarlos hasta Santo Domingo, y debiendo los Alfaro remitirle las correspondientes licencias para evitar problemas con las autoridades de Santo Domingo ${ }^{81}$. Pocos

77 COTTA DO AMARAL, 1965: 59.

78 Por ejemplo, AHPSe, PNS, leg. 40, f. 666r-v. 4/IX/1531.

${ }^{79}$ AHPSe, PNS, leg. 39, f. 88v-89r. El primer contrato de venta se firmó en Sevilla en 16/XI/1530. Los fiadores de Sancho Caballero fueron su hermano Fernando de la Fuente, y Diego Caballero, ambos vecinos de Sevilla. Otro documento de 22/XII/1530 nos informa de que en realidad Sancho Caballero sólo había actuado en representación del grupo familiar, dado que a él correspondía únicamente la sexta parte de los esclavos, a Fernando de la Fuente la tercera parte y a Diego Caballero la mitad (Catálogo, vol. 6: doc. 1530).

${ }^{80}$ AHPSe, PNS, leg. 39, f. 465v y 466v. 13/II/1531. La operación se llevó a cabo, pues en $9 / \mathrm{III} / 1532$. Alonso Nunes se dio por pagado.

${ }^{81}$ AHPSe, PNS, leg. 1532, f. 225r-228r. 31/III/1531. 
días después, el mismo Alfonso Núñez, actuando de nuevo en nombre de Alonso de la Torre, cerró otra venta de 50 piezas de esclavos con Alonso Caballero y el burgalés Melchor de Carrión, quienes enviaron un barco a cargarlos a Santiago de Cabo Verde ${ }^{82}$.

Resulta evidente que el fracaso de Ehinger y Sayler y el fin de su asiento no son los únicos factores a considerar para explicar y comprender la penetración de los mercaderes judeoconversos andaluces en la trata negrera atlántica. Es cierto que entre 1528 y 1531 la concesión de licencias para pasar esclavos a las Indias estuvo condicionada por el asiento de los alemanes, y los datos exhumados por García Fuentes prueban tanto el estrangulamiento de la concesión de licencias en 1531-1533 como una apertura general a partir de 1534 (año en que se concedieron más de 1.800 licencias, repartidas entre más de sesenta beneficiarios), lo que marca una nueva tendencia que dura al menos hasta $1538^{83}$. Hay otro factor a considerar que Scelle ya apuntó en su día, pues parece existir una relación entre los secuestros de remesas de metales preciosos de la década de 1530 por la Corona a los mercaderes con Indias establecidos en Sevilla y una compensación a los mismos en productos financieros entre los cuales se habrían contado también las licencias para exportar esclavos negros a la América española ${ }^{84}$. Efectivamente, desde 1534 los grandes mercaderes judeoconversos andaluces conseguirán cada vez con más facilidad licencias para sí mismos, y no es casualidad que entre ellos se cuenten los mayores afectados por las confiscaciones, como los hermanos Juan Núñez y Fernando de Jerez (a quienes se secuestraron 460.230 mrs. en 1534-1535), o los hermanos Diego y Alonso Caballero, que en los mismos años fueron afectados en más de 1.2 millones de maravedíes, entre otros ${ }^{85}$. Sin embargo, para que éstos pudieran convertirse en los grandes protagonistas de la trata negrera hacia las Indias de Castilla resulta claro que fue también determinante su decidida actuación para hacerse con los principales cargamentos de esclavos y con las necesarias licencias así como la actuación de los Torres conectando desde el lado de la oferta el sistema esclavista portugués con la élite mercantil judeoconversa andaluza. A partir de 1534, su presencia en tal actividad no cesó de crecer.

Rodrigo de Gibraleón, a quien vimos cargar unos pocos esclavos, comenzó su progresión en la trata a partir de 1528, año en que obtuvo de García de Lerma las veinte licencias que este había conseguido (por cédula de 2 de fe-

82 Catálogo, 2006, vol. 10: doc. 97. 1-IV-1531.

83 GARCÍA FUENTES, 19 (Böhlau, 1982): 23-26. Una reevaluación global tanto del número de licencias como del volumen de esclavos enviados a las Indias en el siglo XVI, en PÉREZ GARCÍA, 2015. Aquí podrá el lector observar la evolución de ambas variables.

${ }^{84}$ SCELLE, 1096, vol. 1: 265-267.

${ }^{85}$ CARRETERO, 2011: 122-131. 
brero de 1528), y que utilizó ese mismo año para enviar otros tantos esclavos negros a las Indias. Al año siguiente remitió otros 45 esclavos, comprando para ello licencias procedentes del paquete de 200 unidades concedidas a Francisco de los Cobos en 1527. En 1530 sólo envió un esclavo, y a partir de 1534 su actividad se reanuda en este trato. De las cédulas de 1534 a favor de Jerónimo Dortal, gobernador del golfo de Paria, consiguió ese mismo año 70 licencias, de las cuales a su vez traspasó 69 a terceras personas (seis a Pedro Caballero, trece a Alonso de Illescas, quince a Juan de Alfaro, dos a Sancho Caballero, otra a Diego de Illescas, diez al burgalés Melchor de Carrión, etc) y sólo utilizó una para enviar un esclavo. En 1534 envió otros 54 esclavos, treinta de ellos gracias a licencias que obtuvo del doctor Rodrigo Núñez de Xerez, que le traspasó las que había obtenido por cédula de 23 de mayo de 1534. En 1535 mandó al menos otros 39 esclavos $^{86}$, y a partir de estos años obtuvo periódicamente licencias de la Corona: dos en 1535; 21 en 1536; 122 en 153787, estas últimas en relación con un préstamo que había tenido que hacer en Valladolid al rey ${ }^{88}$.

Los Alfaro siguieron creciendo como negreros en la década de 1530. Luis Fernández de Alfaro consiguió de la Corona cien licencias en 1534, la mitad de las cuales, al menos, fueron utilizadas por su hijo Juan de Alfaro en 1534 y 1535. Este, que sólo había enviado cinco esclavos a las Indias en 1532, pasó a remitir 33 en 1533 (obteniendo las licencias que Juan de la Torre todavía gestionaba del paquete de Gorrevod), y no menos de 91 en 1534-153589. Además, Juan de Alfaro consiguió licencias para 50 esclavos en $1534^{90}$, otras dos para sendas esclavas blancas en $1535^{91}$, y cien licencias más en $1536^{92}$.

El año 1534 marca también un hito en la carrera de los hermanos Hernando de Xerez y Juan Núñez como negreros. Don Cristóbal Ponce de León y Francisco de Santillán, que habían obtenido cada uno 20 licencias en sendas cédulas reales (dadas en Toledo a 21 de mayo de 1534), las traspasaron a Hernando de Jerez al día siguiente en la misma ciudad de Toledo. Asimismo, Hernando de Jerez consiguió otras veinte licencias que le vendió Pero Sánchez, un vecino de Sevilla que era beneficiario de otra cédula de 21-V-1534 para llevar a las Indias 80 esclavos negros. Con estas sesenta licencias, Hernando hizo los correspondientes registros el 20 de julio de 1534 en la Casa de

\footnotetext{
${ }^{86}$ Para todo lo anterior, AGI, C, leg. 5760, libros 1 y 2.

87 GARCÍA FUENTES, 19 (Böhlau, 1982): 25-26.

88 SCELLE, 1906, vol. 1: 267.

${ }^{89}$ AGI, C, leg. 5760, libros 1 y 2.

${ }^{90}$ Cédula de 18-IV-1534. AGI, IG, 422, L. 16, f. 88r.

${ }^{91}$ Cédulas de 22-I-1535 y 23-III-1535. AGI, IG, 1961, L. 3, f. 204r-v y 250v.

92 AGI, IG, 1962, L. 5, f. 29v-30v.
} 
la Contratación para transportar sesenta negros a las Indias ${ }^{93}$. Pero además, Juan Núñez y Hernando de Jerez consiguieron sendas cédulas (también de Toledo, 21 de mayo de 1534) para enviar 20 y 50 esclavos negros a las Indias respectivamente. Con ellas, Juan Núñez cargó dos esclavos ese mismo año, y obtuvo beneficios traspasando las otras 18 licencias a cinco negociantes, que embarcaron los correspondientes esclavos ese mismo año ${ }^{94}$. Por otra parte, con las 50 licencias de Hernando de Jerez, los dos hermanos cargaron ese mismo año otros 20 esclavos, vendiendo las restantes treinta licencias a siete negreros diferentes (uno de los cuales era Alonso Caballero) ${ }^{95}$. Además de otras cédulas conseguidas en 1534-153596, a partir de este momento los dos hermanos supieron conseguir otras muchas tanto de la Corona ${ }^{97}$ como comprándolas a particulares ${ }^{98}$.

También Diego y Alonso de Illescas cargaron esclavos a las Indias en estos años, y desde 1534-1535 comenzamos a documentar a los Jorge en la misma actividad. Fernán Sánchez Dalvo compró 200 licencias en 1537 por 1.300 ducados a doña María de Toledo99, virreina de las Indias, que ésta había conseguido poco antes ${ }^{100}$. Los Caballero, por su parte, continuaron en estos años lucrando licencias y cargando esclavos ${ }^{101}$. En 1538, por ejemplo, Alonso Caballero y el burgalés Melchor de Carrión obtuvieron otro centenar de licencias de doña María de Toledo, para llevar esclavos a La Española ${ }^{102}$; también se hizo con 300 de las 400 licencias concedidas por cédula de 26 de agosto de 1537 a Cristóbal Francesquín, traspasando un centenar a Juan de Escalante, Melchor de Carrión y Gómez de Morales (quienes las registraron en 1538), y enviando a Santo Domingo la documentación correspondiente a otras 130 licencias «por si acaso enviare en alguna nao o carabela portuguesa o destos reynos se llevaren a su nombre alguna cantidad de esclavos negros» ${ }^{103}$. Las operaciones de la familia Caballero siguieron siendo muy importantes durante las dos décadas siguientes ${ }^{104}$.

${ }_{93}$ AGI, C, leg. 5760, libro 1.

${ }^{94}$ AGI, C, leg. 5760, libro 1 y libro 2, f. 21 r.

${ }^{95}$ AGI, C, leg. 5760, libro 1 y libro 2, f. 5r.

${ }^{96}$ GARCİA FUENTES, 19 (Böhlau, 1982): 24.

${ }^{97}$ Por ejemplo, una cédula de 1536 les permitía enviar a las Indias desde Guinea y Cabo Verde 200 licencias que habían sido transferidas de las del gobernador del Río de la Plata (AGI, IG, 422, L.17, f. 39v-40v. 4/IX/1536). En los años cuarenta, Juan Núñez llegó a conseguir de la Corona varios centenares de licencias.

${ }_{98}$ Así, en 16/IV/1537 obtuvieron en Sevilla dieciséis licencias de cuatro beneficiarios (AHPSe, PNS, leg. 11517, f. 533r-539r).

99 Catálogo, 1930, vol. 2: docs. 187 y 188. 4/XII/1537.

100 GARCÍA FUENTES, 19 (Böhlau, 1982): 26.

${ }^{101}$ AGI, C, leg. 5760, libros 1 y 2.

${ }^{102}$ Catálogo, 1930, vol. 2: doc. 294. 13/VI/1538.

103 AGI, C, leg. 5760, libro 2, f. 206-209.

${ }^{104}$ FERNÁNDEZ CHAVES, PÉREZ GARCÍA, 2011: 232-235. 
Un síntoma claro de la capacidad económica que había adquirido la élite mercantil judeoconversa andaluza y el papel que ocupaba en la trata negrera a estas alturas, es la propuesta que en 1536 realizan conjuntamente Alonso Caballero y Gaspar de Torres (ambos vecinos de Sevilla y hermano este último de Alonso y Diego de Torres) para obtener de la Corona el monopolio para llevar 4.000 esclavos negros a las Indias pagando por ello 26.000 ducados. Con ella planteaban una alternativa a la oferta que el poderoso financiero Rodrigo de Dueñas, de Medina del Campo, en asociación con Ehinger, hacía en aquel momento para conseguir una nueva concesión monopolística ${ }^{105}$. A pesar de que ninguna de estas propuestas acabó fructificando, lo cierto es que los mercaderes andaluces demostraban capacidad para competir con quien fue el mayor banquero castellano de la España del emperador, gran asentista y arrendador de diferentes rentas de la Corona ${ }^{106}$. Además, la aparición como vecino de Sevilla de otro hijo de Fernando de Córdoba, Gaspar de Torres, nos avisa del nuevo salto que los conversos andaluces estaban realizando en el escenario negrero del Atlántico. En efecto, la actuación de Gaspar de Torres fue decisiva, pues no sólo se convirtió en el principal captador de licencias del mercado, sino en un ágil animador del tráfico. Adquirió los mayores paquetes de licencias vendidos por la Corona en esos años, además de otros de diversa entidad, enviando gran número de esclavos y revendiendo licencias a grandes y pequeños tratantes. Así, se hizo con las 1.000 licencias que por cédula de 4 de marzo de 1535 había obtenido el portugués Diego Martínez, banquero de Sevilla; Gaspar, a su vez, traspasó 23 de estas licencias a Alonso Núñez (el cual a su vez entregó 19 a Alonso Caballero) y otras 90 a Alonso Caballero, quien registró por su cuenta 27 esclavos y otros 50 junto con el burgalés Melchor de Carrión, a quien además traspasó otras doce licencias ${ }^{107}$. En la misma época obtuvo otras 70 licencias de las 200 que tenía Juan Galvarro, que a su vez las había conseguido de la cédula real de 30 de mayo de 1535 a favor de los alemanes Enrique Ehinger y Alberto Cuan[?]; de ellas utilizó 41 para registrar esclavos en la Casa de la Contratación en mayo de 1537, y al menos otras 22 las traspasó a terceras personas ${ }^{108}$. Poco después Gaspar de Torres adquirió el mayor paquete de licencias de la década de 1530, que constaba de 1.500 unidades: vendido por el rey a los banqueros Cristóbal Francesquín y Diego Martínez, vecinos de Sevilla, por la suma de

${ }^{105}$ AGI, IG, leg. 2795. 2-XI-1536. También SCELLE, 1906, vol.1: 177-178, 188-189, 200; RAMOS, 81 (San José, 1976): 75-77.

106 CARANDE, 2004: 460.

${ }^{107}$ AGI, C, leg. 5760, libro 2, f. 153r. En el mismo año de 1535 las 1.000 licencias pasaron de Diego Martínez a Melchor Letón, caballero de la Casa del Infante D. Luis, el cual las vendió a su vez a Gaspar de Torres (AHPSe, PNS, leg. 10554, f. 441r. 17/XI/1535).

${ }^{108}$ AGI, C, leg. 5760, libro 2, f. 182. 
9.750 ducados (a 6'5 ducados la pieza, un precio de partida elevado); la proximidad entre la fecha de la cédula real a favor de éstos (9 de junio de 1537) y la del traspaso a Gaspar de Torres (23 de junio de 1537), hace pensar que se trataba de una operación previamente preparada en connivencia con este último. La cédula contenía ventajosas condiciones, pues daba permiso para que los esclavos pudiesen ser llevados a las Indias en barcos lusos tripulados por personal portugués, lo que facilitaba la práctica negrera. La voluntad de simplificar al máximo la materialización de la trata explica que entre octubre de 1537 y agosto de 1539 Gaspar de Torres compareciese hasta en cinco ocasiones en la Casa de la Contratación para solicitar que los documentos correspondientes a un total de 1.096 licencias estuviesen disponibles en Santo Domingo de La Española, para el caso de que llegasen allí barcos portugueses procedentes de Guinea con esclavos sin registrar consignados a su nombre; ello delata la rapidez con que se estaban ya realizando los envíos y el perfecto funcionamiento del engranaje negrero montado conjuntamente sobre las estructuras de ambos imperios ibéricos; otras 221 licencias le sirvieron para registrar él mismo esclavos en la Casa de la Contratación ${ }^{109}$. Gaspar de Torres demostraba una y otra vez suficiente capacidad para superar los obstáculos legales que suponía una actividad mercantil organizada desde el imperio portugués hacia el interior del monopolio castellano en Indias; así, una cédula de 31 de mayo de 1541 ordenaba a la Audiencia de La Española que permitiese que los barcos portugueses con gente portuguesa que Gaspar utilizaba para enviar sus esclavos (se dice que en ese momento tenía 1.200 licencias) pudiesen cargar azúcar, cueros, oro, plata y otras mercancías, siempre que volviesen a Sevilla y respetasen las ordenanzas de la Casa de la Contratación ${ }^{110}$.

Los Torres y los Caballero encauzaron una parte importante de la trata en función de sus propias necesidades de mano de obra. De ahí su interés en enviar esclavos a La Española, donde tenían intereses azucareros. Diego Caballero, contador de La Española, y regidor de Santo Domingo desde 1531 hasta 1535 (año en que regresó a España con mercancías valoradas en 20.000 ducados $)^{111}$, llegó a poseer tres ingenios, después de enormes esfuerzos humanos y económicos ${ }^{112}$. Los Caballero y los Torres se abastecieron a sí mismos de esclavos, reduciendo de esta forma los costes de sus inversiones. Hacia 1560, el contador Álvaro Caballero, posiblemente el hombre más poderoso de la isla en ese momento, era dueño de dos ingenios y un trapiche. Melchor de Torres, otro de los hijos de Fernando de Córdoba, poseía tres ingenios en los que trabajaban 430 esclavos, exportando grandes cantidades de azúcar hacia

\footnotetext{
${ }^{109}$ AGI, C, leg. 5760, libro 2, f. 194r-198.

${ }^{110}$ AGI, SD, 868, L. 2, f. 105v. Talavera, 31/V/1541.

111 OTTE, 2003: 322-323.

112 DEL RÍO, 1991: 347.
} 
Sevilla; según otro documento, en 1568 Melchor de Torres poseía alrededor de 900 esclavos en dos grandes ingenios cerca de Santo Domingo ${ }^{113}$. Cuando comenzó la gran crisis de la economía de La Española a comienzos de los años 40, algunos dueños de ingenios y de esclavos solicitaron a la Corona poder vender sus esclavos en el continente, como Hernando Gorjón, enemigo de Álvaro Caballero, que en carta de 1542 pedía que la licencia que había obtenido para llevar 150 negros a La Española se hiciera extensiva a Tierra Firme, «porque en el cabo de Honduras se han descubierto muy buenas minas de oro y tienen valor los esclavos» ${ }^{114}$. Pero quienes aprovecharon de nuevo aquella coyuntura fueron los Torres. En efecto, en 1541 Alonso y Diego de Torres firmaron el acuerdo para introducir 300 esclavos negros en Honduras, y al año siguiente enviaron un cargamento de 180 esclavos; poco después llegó al puerto de Trujillo otro de 175 esclavos en una carabela portuguesa procedente de Santo Domingo enviados por Melchor de Torres, si bien 70 de ellos venían ilegalmente sin las necesarias licencias. De esta manera, los Torres contribuyeron al desarrollo del espectacular ciclo del oro de Honduras ${ }^{115}$, del que no dejaron de beneficiarse ${ }^{116}$. Para entonces los Torres no solo no padecían la crisis de La Española, sino que eran acreedores en la misma de importantes cantidades ${ }^{117}$.

La Española fue una pieza clave para los negocios negreros de los Caballero y los Torres, quienes la utilizaron para dar cobertura a aquellos. En 1541, el contador Álvaro Caballero, en nombre de los vecinos y moradores de La Española, solicitó y obtuvo del emperador licencia para pasar 2.000 esclavos negros a la isla al precio de cinco ducados por licencia, pudiendo utilizarse barcos y tripulaciones portuguesas. Pero la misma cédula reconocía que dado que los habitantes no podían pagar tal cantidad, Álvaro Caballero, por sí y en nombre de todos ellos, nombraba a Cebrián de Caritate, un hombre de negocios que emerge con fuerza en la Sevilla de los años treinta, para que se hiciera cargo tanto del pago como de los envíos, que se circunscribían exclusivamente a dicha isla118. Poco después, Alonso de Illescas, actuando en representación de Caritate, hizo una oferta que la Corona aceptó: de la primera cargazón que llevase, entregaría gratuitamente 40 esclavos negros para la construcción de la fortaleza de la ciudad de Santo Domingo; a cambio, el Rey le otorgaba otras 480 licencias libres de derechos y que podría mandar a cual-

113 RATEKIN, 34/1 (Durham, 1954): 15.

${ }^{114}$ RODRÍGUEZ MOREL, 52/2 (Sevilla, 1995): 214.

115 FERNÁNDEZ, PÉREZ, 25 (Madrid, 2012): 211.

116 AGI, IG, 541, L. 2, f. 17v-18v. 26/VII/1542.

117 AGI, SD, 868, L. 2, f. 156v. Cédula de 1/V/1543.

118 AHPSe, PNS, leg. 3342, f. 244. Cédula de 15/IV/1541, copiada en Sevilla a 19/V/1541. 
quier lugar de las Indias ${ }^{119}$. Sin embargo, quien finalmente acabó enviando la mayor parte de todos estos esclavos, fueron, de nuevo, los Caballero y los Torres. En efecto, tan solo un mes más tarde, Caritate traspasó 700 de las 2.000 licencias a Alonso Caballero ${ }^{120}$, y vendió otras 900 a Gaspar de Torres por 3.600 ducados, a pagar en 1542 y 1543, como así hizo ${ }^{121}$. Ello indica que, en realidad, nos hallamos ante una compleja operación financiera planeada por estos judeoconversos para abaratar el precio de las miles de licencias que utilizaban. En efecto, Álvaro Caballero instrumentalizó su posición de poder en La Española para conseguir que la inicial venta por la Corona de 2.000 licencias bajo el supuesto del desarrollo económico de la isla acabase generando 480 licencias gratis a Caritate y 1.600 licencias a su pariente Alonso Caballero y a Gaspar de Torres a un precio ciertamente inferior al de mercado y a los impuestos habitualmente cobrados por la propia Monarquía. Para ello, Caritate jugó hábilmente con la doble expectativa de pagar las 2.000 licencias y la de entregar 40 esclavos gratis, lo que le hizo ganar 480 licencias sin coste alguno. El beneficio de esta operación compensaba sobradamente el hecho de que las primeras 2.000 licencias hubieran de pagarse a cinco ducados (un precio no demasiado caro) y las vendidas finalmente a Torres lo fueran sólo a cuatro.

\section{CONCLUSIONES: LA CULMINACIÓN DE UN PROCESO, CA. 1540-1560}

A comienzos de la década de 1540 culminaba todo un proceso de ascenso económico protagonizado por los comerciantes sevillanos, entre los que destacaba una serie de familias judeoconversas de las que hemos tratado en este trabajo. El hecho de que en 1541 Diego Caballero y Rodrigo de Illescas se hicieran con el arrendamiento del disputado monopolio de la fabricación del jabón sevillano por un decenio es todo un símbolo, pues durante medio siglo había estado en manos de genoveses, ingleses y alemanes, habiendo intentado hacerse con él, en vano, hombres de negocios burgaleses (como Álvaro de la Torre), de Medina (como Rodrigo de Dueñas), y, por supuesto, andaluces (como Diego de Torres); únicamente Juan Díaz de Alfaro había conseguido entrar en el arrendamiento, pero sólo en 1521-1522122.

La creación del Consulado de Sevilla en 1543 sanciona el éxito económico de un grupo que veía de esta manera reconocido su poder y su contribución

${ }^{119}$ AHPSe, PNS, leg. 3342, f. 247r-249r. Cédula de 6/V/1541, copiada en Sevilla a 19/V/1541.

120 AHPSe, PNS, leg. 3343. 14/VI/1541.

${ }^{121}$ AHPSE, PNS, leg. 3343, f. 548r-v. 14/VI/1541.

122 OTTE, 1996: 67-68. 
económica a la Monarquía, al tiempo que recompensado por las requisas de metales preciosos de las Indias con que había «servido» al Rey ${ }^{123}$. No es casualidad que en el memorial presentado en 1536 en la Casa de la Contratación por los comerciantes sevillanos quejándose de dichos secuestros, encontremos, entre otros, a los conversos Juan de Alfaro, Alonso Alemán, García de Gibraleón, Rodrigo de Illescas, Juan de la Barrera, Gaspar de Torres, Juan Núñez, Gonzalo Jorge, y diferentes miembros de la familia Xerez, sobresaliendo sobre otros grupos como burgaleses o toledanos ${ }^{124}$. Otros documentos, como el poder de los mercaderes con Indias que, agrupados por origen, nombraba en 1538 a 18 de ellos para cobrar la avería del 1\% con objeto de prevenir el ataque de los corsarios franceses, vuelve a poner sobre la mesa el predominio de los judeoconversos en el comercio sevillano, pues los vecinos de Sevilla designados eran Alonso de Illescas, Fernando Sánchez Dalvo, Juan de Alfaro, Rodrigo de Gibraleón, Juan Núñez de Jerez, Pedro Gutiérrez, Rodrigo de Illescas y Cebrián de Caritate ${ }^{125}$. Este último fue, finalmente, quien actuó de portavoz del comercio hispalense en la solicitud que culminó con la creación del Consulado ${ }^{126}$.

Los datos de esclavos enviados a las Indias de Castilla en el periodo 15441550 según los registros de la Casa de la Contratación (Tabla 1), conocidos por la historiografía ${ }^{127}$ aunque con diversos errores en la interpretación y análisis de la documentación del Archivo de Simancas ${ }^{128}$, ponen de relieve el predominio aplastante alcanzado en estas fechas por las grandes familias de mercaderes judeoconversos andaluces en la trata negrera hacia las Indias.

Las grandes familias mercantiles judeoconversas de la Baja Andalucía, ya claramente centradas en la ciudad de Sevilla, fueron responsables de dos terceras partes de los envíos de esclavos negros hacia las Indias de Castilla durante estos años y siguieron jugando un papel decisivo en la década de $1550^{129}$ y al menos hasta la quiebra de los Jorge en $1567^{130}$. Fueron ellos quienes supieron hacer funcionar al unísono la trata africana portuguesa y la nueva trata que nació hacia América en la época de Carlos $V$, desarrollándola hasta convertir el comercio de esclavos en el Atlántico en un gigantesco negocio de dimensiones sin precedentes. Ellos fueron los verdaderos creadores

${ }^{123}$ HEREDIA HERRERA, 1992, vol. 4: 43; VILA VILAR, 1992, vol. 4: 58-61.

124 VILA VILAR, 1992, vol. 4: 59-60.

125 OTTE, 47 (Sevilla, 1990): 121.

${ }^{126}$ HEREDIA HERRERA, 1992, vol. 4: 39-40.

127 A partir de AGS, CJH, leg. 23, los datos han sido utilizados y analizados por: MIRA CABALLOS, 54/201 (Madrid, 1994). CORTÉS LÓPEZ, 8 (Madrid, 1995). MATEUS VENTURA 1999: 53-72 y 121-133.

128 PÉREZ GARCÍA, 2015.

${ }^{129}$ FERNÁNDEZ CHAVES, PÉREZ GARCÍA 2011: 232-233.

${ }^{130}$ LORENZO SANZ, 1979, vol. 1: 289-309. 
TABLA 1. Participación de mercaderes judeoconversos andaluces en la trata negrera hacia las Indias de Castilla, 1544-1550.

\begin{tabular}{|c|c|c|}
\hline Nombre & $\begin{array}{l}\mathrm{N}^{\mathrm{o}} \text { de esclavos } \\
\text { enviados }\end{array}$ & $\begin{array}{l}\% \text { sobre el total de } \\
\text { enviados en el periodo } \\
\text { (13.383 esclavos })\end{array}$ \\
\hline El jurado Gaspar de Torres & 2.317 & $17^{\prime} 3$ \\
\hline Gonzalo y Gaspar Jorge (hermanos) & 1.143 & $8{ }^{\prime} 5$ \\
\hline $\begin{array}{l}\text { Gonzalo y Gaspar Jorge en compañía } \\
\text { con otros mercaderes }\end{array}$ & 170 & 1 '2 \\
\hline $\begin{array}{l}\text { Juan Núñez y Hernando de Jerez } \\
\text { (hermanos) }\end{array}$ & 1.165 & $8^{\prime} 7$ \\
\hline Nombre & $\begin{array}{l}\mathrm{N}^{\mathrm{o}} \text { de esclavos } \\
\text { enviados }\end{array}$ & $\begin{array}{l}\% \text { sobre el total de } \\
\text { enviados en el periodo } \\
\text { (13.383 esclavos })\end{array}$ \\
\hline $\begin{array}{l}\text { Francisco Núñez Pérez y su hermano } \\
\text { Alonso Núñez }\end{array}$ & 760 & $5^{\prime} 6$ \\
\hline El mariscal Diego Caballero & 601 & $4^{\prime} 5$ \\
\hline $\begin{array}{l}\text { Diego Caballero en compañía con } \\
\text { otros mercaderes }\end{array}$ & 181 & $1 ' 3$ \\
\hline Rodrigo Baço & 204 & $1 ' 5$ \\
\hline $\begin{array}{l}\text { Rodrigo Baço con Bartolomé de } \\
\text { Xerez }\end{array}$ & 115 & $0^{\prime} 8$ \\
\hline El jurado Juan de la Barrera, el Mozo & 131 & $0 \prime 97$ \\
\hline $\begin{array}{l}\text { Andrés de Paradas, Belchior Barreto } \\
\text { y Alonso de la Barrera }^{131}\end{array}$ & 1.697 & $12^{\prime} 68$ \\
\hline Otros & 415 & $3 \prime 1$ \\
\hline TOTAL & 8.899 & $66^{\prime} 5 \%$ \\
\hline \multicolumn{3}{|c|}{$\begin{array}{l}\text { Otros: Diego Alemán: 30; Sancho Caballero y Diego Alemán: 12; Alonso de Illes- } \\
\text { cas: 10; Rodrigo de Illescas: 22; Hernán Sánchez de la Barrera: 43; Francisco Nú- } \\
\text { ñez de Illescas: 100; Luis Sánchez Dalvo: 89; Gonzalo Jorge de México y su yerno } \\
\text { Juan Díaz de Gibraleón: 19; Álvaro Caballero: 10; Juan Caballero: 2; Ruy Díaz de } \\
\text { Gibraleón: 50; Bartolomé de Xerez: 3; Hernando de Xerez de Baeza: } 25 \text {. }\end{array}$} \\
\hline
\end{tabular}

Fuente: Elaboración propia a partir de AGS: CJH, leg. 23.

${ }^{131}$ En el caso de esta compañía, que envía esclavos entre 1544-1548, la hemos incluido por formar parte de ella el sevillano Alonso de la Barrera. Estos individuos consiguieron 2.250 licencias en 1540-1546 (SCELLE, 1906, vol. 1: 228-229). 
de una trata que en la década de 1550 continuó metamorfoseándose, al igual que ellos. Mientras se producía en el seno de estas familias conversas un amplio relevo generacional (Hernando de Xerez murió en 1548, el mariscal Diego Caballero lo hizo en 1560, y Alonso de Illescas en 1562) que no interrumpió su ascenso en la sociedad sevillana, los mercaderes portugueses comenzaron a penetrar con mayor profundidad en la economía sevillana, aprovechando precisamente su papel clave en el suministro de esclavos ${ }^{132}$. Los tiempos cambiaban, y la trata castellana se desplazaba de manos de los conversos andaluces a la de los mercaderes lusos ${ }^{133}$.

\section{Bibliografía}

Almeida Mendes, António de, «Portugal e o tráfico de escravos na primera metade do século XVI», Africana Studia, 7 (Porto, 2004), 13-30.

Armenteros Martínez, Iván, La esclavitud en Barcelona a fines de la Edad Media (1479-1516), Tesis doctoral, Universitat de Barcelona, 2012.

Bejarano Robles, Francisco, Documentos para el estudio del abastecimiento y auxilio de las plazas portuguesas en Marruecos, desde el sur de España, Tánger, Publicaciones del Instituto General Franco para la investigación Hispano-Árabe, 1941.

Cabral, Iva Maria, Ferraz Torrão, Maria Manuel, «Ensaios de uma feitoria régia no espaço económico e social da ilha de Santiago (1520-1550)», Stvdia, 54-55 (Lisboa, 1996), 33-49.

Carande, Ramón, Carlos Vy sus banqueros, Barcelona, Crítica, 2004.

Carretero Zamora, Juan Manuel, «Los conversos y la Hacienda de Castilla a comienzos del siglo XVI», en Raphaël Carrasco, Annie Molinié y Béatrice Perez (dir.), La pureté de sang en Espagne. Du lignage à la «race», Paris, PUPS, 2011; 113-131.

Casado Alonso, Hilario, El triunfo de Mercurio. La presencia castellana en Europa (Siglos XV y XVI), Burgos, Cajacírculo, 2003a.

Casado Alonso, Hilario, «Los seguros marítimos de Burgos. Observatorio del comercio internacional portugués en el siglo XVI», História. Revista da Faculdade de Letras, 4 (Porto, 2003b), 213-242.

Catálogo de los fondos americanos del Archivo de Protocolos de Sevilla, Sevilla, Instituto Hispano-Cubano de Historia de América, 1930-2014, 13 vols.

Caunedo del Potro, Betsabé, «Operaciones comerciales del grupo familiar Castro a finales del siglo XV», En la España medieval, 5 (Madrid, 1986), 289-298.

Cohen, Zelanda, «Os contratos de arrendamento para a cobrança das rendas e direitos reais das ilhas de Cabo Verde (1501-1560)», Stvdia, 53 (Lisboa, 1994): 317-364.

Corte-Real, Manuel Henrique, A feitoria portuguesa na Andaluzia (1500-1532), Lisboa, Instituto de Alta Cultura, 1967.

132 FERNÁNDEZ CHAVES, PÉREZ GARCÍA, 2010; 25 (Madrid, 2012).

133 PÉREZ GARCÍA, FERNÁNDEZ CHAVES 2009. 
Cortés Alonso, Vicenta, La esclavitud en Valencia durante el reinado de los Reyes Católicos (1479-1516), Valencia, Ayuntamiento de Valencia, 1964.

Cortés López, José Luis, «1544-1550: el periodo más prolífico en la exportación de esclavos durante el s. XVI. Análisis de un interesante documento extraído del Archivo de Simancas», Espacio, Tiempo y Forma, Serie IV, $H^{a}$. Moderna, 8 (Madrid, 1995), 63-86.

Cortés López, José Luis, Esclavo y colono. Introducción y sociología de los negroafricanos en la América española del siglo XVI, Salamanca, Universidad de Salamanca, 2004.

Cotta do Amaral, Maria Valentina, Privilégios de mercadores estrangeiros no reinado de D. João III, Lisboa, Universidade de Lisboa, 1965.

Fernández Chaves, Manuel F., Pérez García, Rafael M., «Las redes de la trata negrera. Mercaderes portugueses y tráfico de esclavos en Sevilla (c. 1560-1580)», en Aurelia Martín Casares y Margarita García Barranco (comps.), La esclavitud negroafricana en la historia de España. Siglos XVI y XVII, Granada, Editorial Comares, 2010; 5-34.

Fernández Chaves, Manuel F., Pérez García, Rafael M., «América como mecanismo de transformación y movilidad social en la Sevilla Moderna: los Caballero de Cabrera», en Miguel Jasmins Rodrigues y María Manuel Torrão (orgs.), Pequena Nobreza de Aquém e de Além Mar, Lisboa, IICT, 2011; 221-252.

Fernández Chaves, Manuel F., Pérez García, Rafael M., «La penetración económica portuguesa en la Sevilla del siglo XVI», Espacio, Tiempo y Forma. Serie IV, Historia Moderna, 25 (Madrid, 2012), 199-222.

Ferraz Torrão, Maria Manuel, «Os portugueses e o trato de escravos de Cabo Verde com a América espanhola no final do século XVI», en Pedro Cardim, Leonor Freire Costa y Mafalda Soares da Cunha (orgs.), Portugal na Monarquia Hispãnica. Dinãmicas de integração e conflito, Lisboa, CHAM, 2013; 93-106.

Fonseca, Jorge, Escravos e Senhores na Lisboa Quinhentista, Lisboa, Edições Colibri, 2010.

Franco Silva, Alfonso, La esclavitud en Sevilla y su tierra a fines de la Edad Media, Sevilla, Diputación Provincial de Sevilla, 1979.

García Fuentes, Lutgardo, «Licencias para la introducción de esclavos en Indias y envíos desde Sevilla en el siglo XVI», Jahrbuch für Geschichte von Staat, Wirtschaft und Gesellschaft Lateinamerikas, 19 (Böhlau, 1982), 1-46.

Gil, Juan, Los conversos y la Inquisición sevillana, Sevilla, Fundación El Monte, 2000-2003, 8 vols.

Godinho, Vitorino Magalhães, Os descobrimentos e a economia mundial, Lisboa, Editorial Presença, 1991, 4 vols.

González Arévalo, Raúl, La esclavitud en Málaga a fines de la Edad Media, Jaén, Universidad de Jaén, 2006.

Heredia Herrera, Antonia, «El Consulado de mercaderes de Sevilla, una institución 'retrasada' del Descubrimiento», en Actas del Congreso de Historia del Descubrimiento, Madrid, Real Academia de la Historia y Confederación Española de Cajas de Ahorro, 1992, t. 4; 35-51. 
Ladero Quesada, Miguel Ángel, «Sevilla y los conversos: los 'habilitados’ en 1495», Sefarad, 52/2 (Madrid, 1992), 429-447.

Lobo Cabrera, Manuel, «Mercaderes de Burgos en Canarias: Francisco Manrique», Anuario de Estudios Atlánticos, 36 (Madrid - Las Palmas, 1990), 493-513.

López Beltrán, María Teresa, «Redes familiares y movilidad social en el negocio de la renta: el tándem Fernando de Córdoba-Rodrigo Álvarez de Madrid y los judeoconversos de Málaga», Revista del Centro de Estudios Históricos de Granada y su Reino, 24 (Granada, 2012), 33-72.

López Beltrán, María Teresa, González Arévalo, Raúl, «Los portugueses en el Reino de Granada en época de los Reyes Católicos, 1487-1518», Baetica. Estudios de Arte, Geografía e Historia, 24 (Málaga, 2002), 309-338.

López de Coca Castañer, José Enrique, «Mercaderes genoveses en Málaga (14871516). Los hermanos Centurión e Ytalian», Historia. Instituciones. Documentos, 7 (Sevilla, 1980), 95-123.

Lorenzo Sanz, Eufemio, Comercio de España con América en la época de Felipe II, Valladolid, Diputación Provincial de Valladolid, 1979, 2 vols.

Martín Acosta, Emelina, «La carrera indiana de un prohombre burgalés: García de Lerma», Boletín de la Institución Fernán González, 73/1 (Burgos, 1994), 39-52.

Mateus Ventura, Maria da Graça A., Negreiros portugueses na rota das Índias de Castela (1541-1556), Lisboa, Edições Colibri, 1999.

Mira Caballos, Esteban, «Las licencias de esclavos negros a Hispanoamérica (15441550)», Revista de Indias, 54/201 (Madrid, 1994), 273-297.

Montes Romero-Camacho, Isabel, «La huida de judeoconversos sevillanos a Portugal como consecuencia del establecimiento de la Inquisición», en Estudos em Homenagem ao Professor Doutor José Marques, Porto, Universidade do Porto, 2006, vol. 2 ; 263-289.

Ollero Pina, José Antonio, «Una familia de conversos sevillanos en los orígenes de la Inquisición: los Benadeva», Hispania Sacra, 40 (Madrid, 1988), 45-105.

Otte, Enrique, «Die Negersklavenlizenz des Laurent de Gorrevod», Spanische Forschungen der Görresgesellschaft, 22 (Münster, 1965), 283-320.

Otte, Enrique, «Mercaderes burgaleses en los inicios del comercio con México», Historia Mexicana, 18/2 (México, 1968), 108-144.

Otte, Enrique, «Los mercaderes transatlánticos bajo Carlos V», Anuario de estudios americanos, 47 (Sevilla, 1990), 95-121.

Otte, Enrique, Sevilla y sus mercaderes a fines de la Edad Media, Sevilla, Universidad de Sevilla y Fundación El Monte, 1996.

Otte, Enrique, «Diego Caballero, funcionario de la Casa de la Contratación», en Antonio Acosta Rodríguez, Adolfo González Rodríguez y Enriqueta Vila Vilar (coords.), La Casa de la Contratación y la navegación entre España y las Indias, Sevilla, Universidad de Sevilla y Fundación El Monte, 2003; 315-339.

Otte, Enrique, Sevilla, siglo XVI: Materiales para su historia económica, Sevilla, Centro de Estudios Andaluces, 2008.

Palenzuela Domínguez, Natalia, Los mercaderes burgaleses en Sevilla a fines de la Edad Media, Sevilla, Universidad de Sevilla, 2003. 
Perez, Béatrice, Inquisition, pouvoir et société. La province de Séville et ses judéoconvers sous les Rois Catholiques, Paris, Honoré Champion, 2007.

Pérez García, Rafael M. y Fernández Chaves, Manuel F. «Sevilla y la trata negrera atlántica: envíos de esclavos desde Cabo Verde a la América española, 15691579», León C. Álvarez Santaló (coord.), Estudios de Historia Moderna en Homenaje al Profesor Antonio García-Baquero, Sevilla, Universidad de Sevilla, 2009; 597-622.

Pérez García, Rafael M., «Metodología para el análisis y cuantificación de la trata de esclavos hacia la América española en el siglo XVI», en O. Rey Castelao y F. Suárez Golán (eds.), Los vestidos de Clío. Métodos y tendencias recientes de la historiografía modernista española (1973-2013), Santiago de Compostela, Universidade de Santiago de Compostela, Servizo de Publicacións e Intercambio Científico, 2015; 823-840.

Pike, Ruth, Enterprise and adventure. The Genoese in Sevilla and the Opening of the New World, Ithaca, Cornell University Press, 1966.

Pike, Ruth, Aristócratas y comerciantes, Barcelona, Ariel, 1978.

Ramos Pérez, Demetrio, «El negocio negrero de los Welser y sus habilidades monopolísticas», Revista de Historia de América, 81 (San José de Costa Rica, 1976), 7-81.

Ramos Pérez, Demetrio, «El grupo financiero de Burgos en el momento que dominó la empresa ultramarina», en Primeras Jornadas de Historia. Burgos y América, Burgos, Caja de Ahorros de Burgos, 1992; 131-157.

Ratekin, Mervyn, «The Early Sugar Industry in Española», The Hispanic American Historical Review, 34/1 (Durham, 1954), 1-19.

Rodríguez Morel, Genaro, «Cartas privadas de Hernando Gorjón», Anuario de Estudios Americanos, 52/2 (Sevilla, 1995), 203-233.

Scelle, Georges, La traite négrière aux Indes de Castille, Paris, 1906, 2 vols.

Soto Artuñedo, Wenceslao, «La familia malagueña 'de Torres' y la Iglesia», Isla de Arriarán, 19 (Málaga, 2002), 163-191.

Vila Vilar, Enriqueta, «Algunas consideraciones sobre la creación del Consulado de Sevilla», en Actas del Congreso de Historia del Descubrimiento, Madrid, Real Academia de la Historia y Confederación Española de Cajas de Ahorro, 1992, tomo 4; 53-65.

Recibido: $27 / 05 / 2014$

Aprobado: 29/12/2015 